\title{
Editorial
}

\section{Journal of Building Construction and Planning Research: A New Platform for Building Researchers}

\author{
Gwang-Hee Kim \\ Department of Plant \& Architectural Engineering, Kyonggi University, Suwon-Si, South Korea. \\ Email: ghkim@kyonggi.ac.kr
}

Received April 13 ${ }^{\text {th }}, 2013$; revised May 15 ${ }^{\text {th }}, 2013$; accepted May 24 ${ }^{\text {th }}, 2013$

Copyright (C) 2013 Gwang-Hee Kim. This is an open access article distributed under the Creative Commons Attribution License, which permits unrestricted use, distribution, and reproduction in any medium, provided the original work is properly cited.

Building construction projects include design, financial, estimating, environmental consideration, and legal review [1]. Building engineering is the application of theory, knowledge, technology, etc. to building construction. Building engineering can be classified into three categories: Structural Engineering, Mechanical, Electrical, and Plumbing (MEP), and Construction. Structural engineering includes the analysis and design of the structural frame. MEP engineering is a significant component of the building supply system and is the most important part of the building, which must be carefully coordinated before design and installation. In the field of architecture, construction consists of construction technology and construction management. Construction technology includes materials engineering, construction methods, etc. Also, construction management is a process encompassing the planning, coordination, and control of design, financial, and estimation of a project, from starting to completion.

Building planning is classified into three categories, which are architectural theory, architectural design, and sustainable architecture design. Architectural theory involves thinking, discussing and writing about architecture [2]. Architectural design is a plan for architecture, i.e. the written documentation and graphical descriptions of building projects. Sustainable architecture refers to ecofriendly design techniques in the field of architecture, and has recently been considered as a priority.

Recently, there has been quite a bit of multidisciplinary convergence between research fields. In building construction and planning, there is a tendency to focus research on the fields of construction engineering and architectural planning. But building construction and planning research clearly cannot be separated from each other, and as such, the cooperation between each field in practices of building construction and planning as well as in research is needed. Building construction and planning is one of the composite arts. Research in the specific field of construction and planning research has been published in specific journals; that is, the scope of journals is quite narrow. Building construction and planning is quite a broad area of study, and as such it is not possible to cover all areas with research papers in one journal. However, the tendency to separate the various fields of building construction and planning may be undesirable for the progress of building construction, and does not match the recent trend of research.

Journal of Building Construction and Planning Research (JBCPR), a new open access journal, will include all areas of building construction and planning fields mentioned above, and will exclude original structural engineering and original MEP engineering. These fields are excluded because they are associated with buildings but are different from HVAC (heating, ventilation, and air conditioning), one of the factors affecting the building environment. All kinds of papers in all fields of building construction and planning, with the exception of these two fields mentioned above, are welcome to submit to JBCPR.

So what makes JBCPR significantly different from other civil engineering or building engineering journals? While other civil engineering or building engineering journals are concentrated on narrow, specific topics such as structural engineering, construction engineering, construction management, or environmental engineering, JBCPR is interested in the convergence of an associated field of study in building construction and planning. Therefore, JBCPR will be particularly interested in publishing articles on: 1) applications of information technology (IT) to building construction and planning; 2) green building design and construction for sustainable architecture; 3) crime prevention design through environmental design for community safety; 4) building de- 
sign management for saving costs and shortening construction duration; 5) passive design for reducing $\mathrm{CO}_{2}$ emission and energy consumption; 6) low energy embodied materials; 7) recycled materials; 8) healthy materials; 9) innovative construction methods; 10) lean construction management; 11) Human-centered construction management, etc. Nevertheless, JBCPR will also publish research papers that is not necessarily highly innovative or novel, and is also interested in: 1) technical notes; 2-5 page papers in which an author can either give an idea with a scientific basis but has not yet completed; 2) book reviews; 3) article reviews; 4) case studies of best practice, etc.

I thank Scientific Research Publishing (SCIRP) for giving me the chance to launch this new journal. Also, I would like to thank all editorial members of JBCPR who have encouraged me in the launch of JBCPR, and who are serving as editorial board members of JBCPR. I hope that JBCPR will be a distinguished journal in the field of building construction and planning, and will become a main platform through which academic scholars, researchers, practitioners, and students can communicate with each other and share their knowledge, experience, study results, and information.

\section{REFERENCES}

[1] Wikipedia, "Building Construction," http://en.wikipedia.org/wiki/Construction

[2] Wikipedia, "Architectural Theory," http://en.wikipedia.org/wiki/Architectural_theory 